\title{
Neutral Mood Induction During Reconsolidation Reduces Accuracy, but Not Vividness and Anxiety, of Emotional Episodic Memories
}

\section{Citation}

Liu, Guanyu. 2015. Neutral Mood Induction During Reconsolidation Reduces Accuracy, but Not Vividness and Anxiety, of Emotional Episodic Memories. Master's thesis, Harvard Extension School.

\section{Permanent link}

http://nrs.harvard.edu/urn-3:HUL.InstRepos:24078359

\section{Terms of Use}

This article was downloaded from Harvard University's DASH repository, and is made available under the terms and conditions applicable to Other Posted Material, as set forth at http:// nrs.harvard.edu/urn-3:HUL.InstRepos:dash.current.terms-of-use\#LAA

\section{Share Your Story}

The Harvard community has made this article openly available. Please share how this access benefits you. Submit a story. 


\title{
Neutral Mood Induction During Reconsolidation Reduces Accuracy, but not Vividness and Anxiety, of Emotional Episodic Memories
}

\author{
Guanyu Liu
}

\author{
A Thesis in the Field of Psychology \\ for the Degree of Master of Liberal Arts in Extension Studies
}

Harvard University

November 2015 
Copyright 2015 Guanyu Liu 


\begin{abstract}
When consolidated memories are reactivated, they become labile and have to go through reconsolidation to become stabilized. This property of memory may potentially be used to reduce the impact of highly negative episodic memories. Because detailed and vivid negative episodic memories are mediated by high arousal, if arousal is lessened during reconsolidation, then memory accuracy and vividness should diminish. In this study, I examine this hypothesis. Participants viewed a stressful, suspenseful movie on Day 1 to develop negative episodic memories. Then, 24 to 29 hours later, they saw a brief reminder of the stressful movie (or not), and then viewed a neutral (or positive) movie. Another 24 to 29 hours later, I tested the accuracy, vividness, and anxiety associated with their memory of the stressful movie. Participants who watched the reminder and then the neutral movie showed reduced memory accuracy. Despite the reduction in memory accuracy, their memory vividness and anxiety associated with the stressful movie did not decrease. The results partly supported my hypothesis.
\end{abstract}


To mom, Shi Yunping, and dad, Liu Jingbo,

without whose love and support, this thesis would not have been possible 


\section{Acknowledgements}

This is my second master's thesis. It is very different than the first one. The first thesis was about business administration. This one is about psychology. It has been 6 years since I wrote the first thesis. A lot of things have changed. For example, I switched fields from Management to Psychology. And I moved from the quiet, sparsely populated Linkoping (Sweden) to the boisterous and densely populated Cambridge (United States). I feel deeply lucky and grateful for the help, guidance, and kindness I received along this journey. And below I shall give my deepest thanks to the people who have offered me help, guidance, and kindness in this stretch of the journey.

First, I would like to thank my supervisor, Professor Richard J. McNally, for his clear and helpful guidance during the thesis process, for his patience while I was busy with the exams and assignments of other classes, for his incisive comments and meticulous corrections on the thesis drafts (such as spotting a typo in a table), and finally, for inculcating an attitude of scholarship in me. Thanks, Rich.

Next, I would like to thank Professor Michael S. Esterman for his careful review and perceptive comments on the thesis proposal as well as his advice on statistical analysis. Also, he suggested that I use Baraka as the neutral film — it worked very effectively.

I would also like to extend my thanks to my research advisor, Professor Dante Spetter, for her careful, thorough edits of my thesis proposal and the final manuscript. Her efforts brought the proposal and manuscript into line with the thesis 
conventions.

My academic advisor, Chuck Houston, answered my numerous questions about the thesis proposal, thesis writing, and the master's program in general. His help is highly appreciated.

My English teacher, Stefanie Morejon, helped organize a film screening to test the movie clips to be used in the experiment. I appreciate her help.

Cynthia Tsai, and Avia Tadmor, the two former thesis writers whose research topic was similar to mine, generously shared their notes, theses, and experimental materials with me. Their wholehearted support is highly appreciated. I would also like to thank Winnie Wu for sharing her ALM thesis proposal.

I would like to thank Michelle Tsai, Mallory Grosso, Chris Chiu, Vicky Poole, Josh Friedman, Elizabeth Mahon, Yoonah Park, Justin Giallorenzo, Heidi Lennings, and Lexy Long for their help in piloting the study before it was finally launched. Also, I thank Phil Enock and Dianne Hezel for their help in rating the valence and arousal of the movies.

Finally, I am deeply indebted and immensely grateful to my parents for their unconditional love and support during the journey. It is their support and sacrifice that has made everything possible — the smooth transition from Management to Psychology, and from Sweden to the US. Not only did they fully trust my judgments, they also made sure that I needed not worry about financing my studies since I went back to school again. Such trust and generosity is not ordinary, it is extraordinary. Thank you and I love you, mom and dad. 
Table of Contents

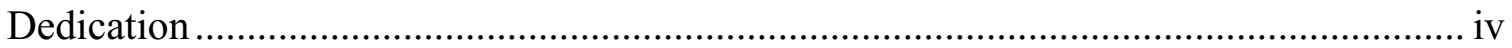

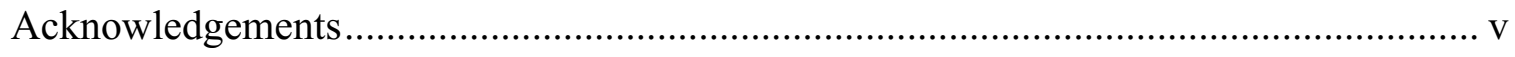

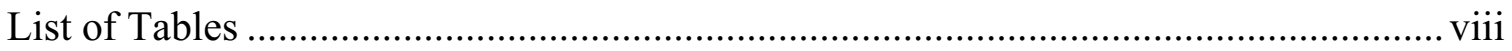

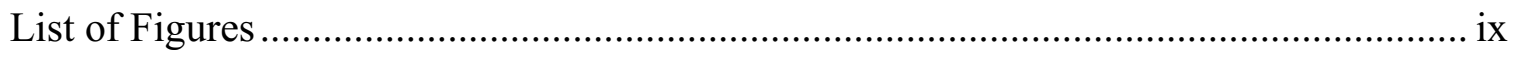

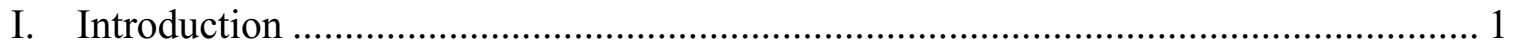

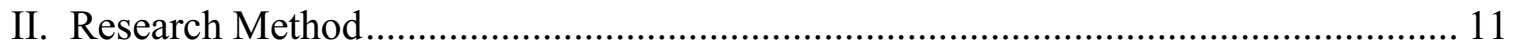

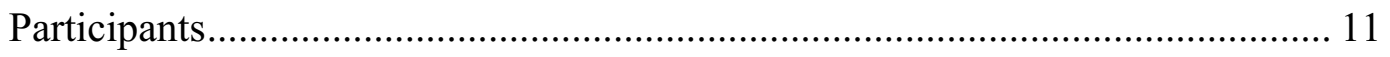

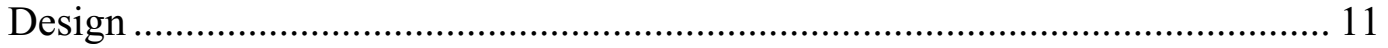

Materials .......................................................................................... 12

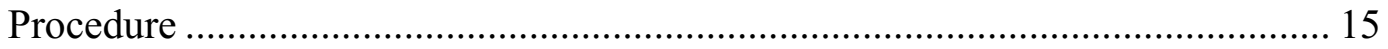

Statistical Analysis.................................................................................. 20

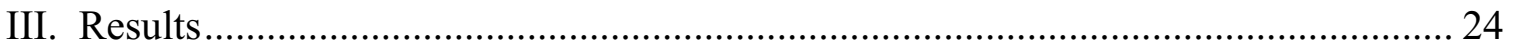

Day 1 — Baseline Measure and Movie Encoding............................................. 24

Day 2 - Memory Reactivation and Mood Induction .................................. 25

Day 3 — Testing Reconsolidation Effects.................................................... 27

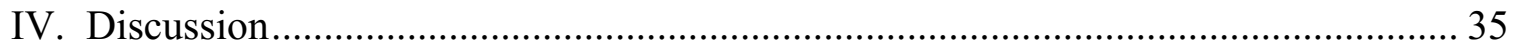

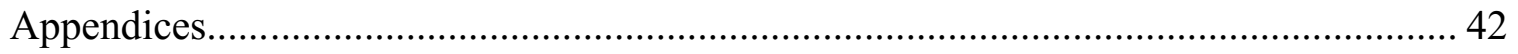

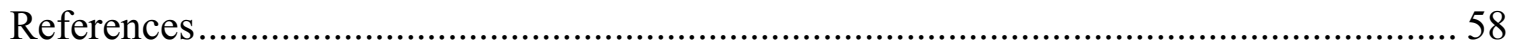




\section{List of Tables}

Table 1 Means and Standard Deviations of Day 1's Measures ............................... 25

Table 2 Means and Standard Deviations of the Valence and Arousal Ratings of the

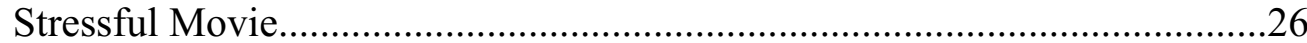

Table 3 Contrasts of Neutral Movie Groups' Valence and Arousal Ratings for the Neutral Movie with Their Valence and Arousal Ratings for the Stressful Movie..................28

Table 4 Contrasts of Positive Movie Groups' Valence and Arousal Ratings for the Positive Movie with Their Valence and Arousal Ratings for the Stressful Movie....28 


\section{List of Figures}

Fig. 1 Experimental Procedure ….................................................................. 21

Fig. 2 Reconsolidation Effect of Memory Accuracy ........................................... 30

Fig. 3 Reconsolidation Effect of Memory Vividness ............................................. 31

Fig. 4 Reconsolidation Effect of Memory Anxiety ….......................................... 32 


\section{Chapter I}

\section{Introduction}

The idea of memories becoming progressively stabilized was first mentioned in Ribot's 1882 book, Diseases of Memory. He described the two organic foundations of memories: modifications upon neurons and stable associations between different groups of neurons (pp. 22-24). From this point of view, memories became strengthened overtime as neurons became more modified and associated with other neurons. As a result of this progressive stabilization, memories became more robust and less susceptible to degradation from disease. This idea was embodied in Ribot's law of regression: "[memory destruction] advances progressively from the unstable to the stable" (p. 121). Burnham (1903) further expounded the law of regression and argued that only after a memory became stabilized could it be reliably reproduced.

Ribot and Burnham's ideas formed the basis of the consolidation hypothesis which states that memories evolve from an early fragile, labile form to an increasingly robust, strengthened form, thereby becoming less vulnerable to external interference (Dudai, 2004; Sara, 2000). Early empirical support for this hypothesis came primarily from retrograde amnesia research on rodents subjected to an inhibitory avoidance paradigm. In a typical experiment, a rodent is placed in the illuminated part (versus the dark part) of a two-compartment chamber. Because rodents naturally favor dark environments, when the door separating the two compartments opens, they will enter the dark compartment. Upon entering, they receive an electric shock. When they are tested 
later, the latency to enter the dark compartment is taken as a measure of fear memory retention (Jones \& Monfils, 2013). Experimental procedures usually include a singletrial avoidance task followed by amnestic treatments (e.g., electroconvulsive shock) at various intervals after training. Results from early experiments revealed that memories were susceptible to being disrupted within 1 to 3 hours after training (depending on shock intensity), and would not be affected if treatments were administered outside this window (McGaugh, 1966; Luttges \& McGaugh, 1967).

Hence, the consolidation hypothesis implies that for any memory, consolidation takes place just once. As soon as memories are consolidated, they become stable and resistant to alteration (Dudai, 2004). New evidence, however, suggests that reactivated long-term memories can once again become labile, and undergo another consolidation process termed reconsolidation (Dudai, 2004; Nader \& Einarsson, 2010; Sara, 2000).

The debate about the reality of reconsolidation has reignited after decades of dormancy (Dudai, 2004). As early as 1968, Misanin, Miller, and Lewis, using the inhibitory avoidance paradigm on rodents, demonstrated that electroconvulsive shock (ECS), when administered after a consolidated memory was reactivated, disrupted the original fear memory and produced retrograde amnesia. This effect occurred only if the consolidated memory was first reactivated. Furthermore, Lewis, Bregman, and Mahan (1972) used a far more complex paradigm, maze learning, to study the same phenomenon. In addition, they used a longer retention interval (7 days) between the initial maze learning and the administration of ECS to allow for robust memory consolidation. Seven days after training, ECS produced amnesia for the maze only if rodents were first presented reminder cues that reactivated the consolidated memory. 
Despite the initial findings, research on memory reconsolidation lost favor for the next two decades, partly because its results were not replicated in other studies (e.g., Squire, Slater, \& Chace, 1976), and partly because "the idea was not easy to reconcile with the zeitgeist" that emphasized the cellular and molecular basis of memory (Dudai, 2004, p. 69).

Interest in memory reconsolidation was rekindled in the late 1990s and began attracting research attention following two highly publicized works by Nader, Schafe, and LeDoux (2000) and Sara (2000). Nader et al., (2000) reasoned that just as the consolidation of fear memory required protein synthesis in the amygdala, its reconsolidation would also require protein synthesis in the amygdala. Hence, if the protein synthesis necessary for reconsolidation was disrupted, the original fear memory would be removed or at least be disrupted.

They used an auditory fear conditioning procedure to train rodents to associate a tone with foot-shock. After the conditioned fear memory was consolidated (i.e., after 1 day), the researchers first exposed the rodents to the tone, thereby reactivating the fear memory. Immediately thereafter, they injected the protein synthesis inhibitor, anisomycin, to the rodents' lateral and basal nuclei of the amygdala to prevent the reactivated fear memory from becoming reconsolidated. When retested, they found that the rodents showed less freezing to the tone, suggesting that the original fear memory was reduced because its reconsolidation was blocked. Furthermore, Sara (2000), in a review article, surveyed previous and contemporary research on memory reconsolidation and presented evidence showing that memory reconsolidation was a legitimate phenomenon. 
The following decade witnessed an increase in memory reconsolidation research involving a variety of animal species (e.g., sea slug, snail, crab) and treatments (e.g., protein synthesis inhibitor, surgical lesions). These studies confirmed the existence of memory reconsolidation (for a review, see Besnard, Caboche, \& Laroche, 2012). The first experiment that demonstrated a reconsolidation effect in humans was conducted by Walker, Brakefield, Hobson, and Stickgold (2003) who studied procedural memory. Procedural memory is long-term memory for actions, both cognitive and motor; procedural memory is implicit and nondeclarative in that it is accessed and used without conscious effort and attention (e.g., walking, breathing) and is thus not expressible in language. Declarative memory, in contrast, is long-term memory for experiences and facts. It refers to memories that can be consciously accessed and recalled (Gray, 2011). It is further divided into episodic memory (i.e., memory for life episodes) and semantic memory (i.e., memory for general facts). In Walker et al. (2003), one group of participants encoded a finger-tapping task on day 1 . On day 2 , they first briefly rehearsed the task (i.e., reactivation) and then learned a new finger-tapping task. When retested on day 3 , they showed significant reduction in accuracy for the finger-tapping task they learned on day 1 . The result suggested that the brief reactivation of a consolidated motor procedural memory returned the memory into a labile state, rendering it vulnerable to interference from a competing motor memory (Walker et al., 2003).

The first experiment on the reconsolidation of human declarative memory was reported by Hupbach, Gomez, Hardt, and Nadel, (2007). The researchers used a 3 day experimental design. Participants learned a list of unrelated objects (e.g., bow, calculator) on day 1, and a second list of objects, 48 hours later, on day 2. On day 2, 
before learning the second list, one group was given a reminder to reactivate their memory of the objects from the first list, while the other group was not given the reminder. The reminder was a blue basket used on day 1 for participants to learn objects of the first list. During the training on day 1, objects on the first list were taken out of a bag and placed in the blue basket one at a time; participants were then instructed to memorize as many objects as possible in the blue basket. When the basket was used as a reminder, participants were asked whether they could remember the basket and what it was used for on day 1 . On day 3 , participants' were tested for their memory of the first list. Results showed that participants who received a reminder before learning the $2 \mathrm{nd}$ list incorrectly mixed more objects from the 2 nd list into the 1 st list. This effect did not occur immediately when subjects were tested on day 2 . The researchers concluded that the reminder reactivated and destabilized memory for list 1 objects and thus allowed more information from list 2 to be incorporated into list 1.

The reconsolidation of emotional declarative memory has also been examined. Schwabe, Nader, and Pruessner (2013) studied the effect of a beta-adrenergic blocker, propranolol, in the reconsolidation of negative episodic memories. The researchers reasoned that emotionally arousing experiences led to more vivid and accurate memories. Hence, if arousal were dampened by propranolol during reconsolidation, the memories would become less vivid and accurate.

The experiment was conducted during three consecutive days, 24 hours apart. Participants were randomly assigned to 4 experimental groups (i.e., placebo/reactivation, placebo/no reactivation, propranolol/reactivation, propranolol/no reactivation). On day 1 , all participants encoded 25 negatively arousing and 25 neutrally toned pictures. On day 
2 , the procedure differed for the 4 experimental groups. Depending on the condition, participants either received a placebo or propranolol and then they were either given a reminder (i.e., they were asked to recall the pictures presented on day 1) or a nonreminder (i.e., they were given newspapers to read). On day 3 , participants completed a recognition test in which they were presented the 50 pictures they encoded on day 1 with 50 new pictures. They were first instructed to indicate whether a given picture was presented on day 1 (in which case they would respond "old"), or on test day (in which case they would respond "new"). They were then asked to indicate, for each "old" picture, whether they clearly "remembered" the picture (i.e., with contextual information), or they simply "knew" the picture because it seemed familiar.

Whereas participants in the placebo/reactivation, placebo/no reactivation, and propranolol/no reactivation groups all showed better memory for negative pictures as opposed to the neutral ones, participants in the propranolol/reactivation group did not exhibit this memory enhancement toward negative pictures, suggesting that the enhancing effect of arousal was blocked during reconsolidation by propranolol after the memory was reactivated. Furthermore, participants in the propranolol/reactivation group showed significantly less "remember" judgments for correctly recognized negative pictures than did participants in the other three groups, suggesting that their memories for the negative pictures became less vivid during reconsolidation.

Similarly, Kroes et al. (2014) examined the effect of electroconvulsive therapy (ECT) in the reconsolidation of negative episodic memories on patients with depression. Forty-two patients were randomly assigned to one of three groups - A, B, C - in which $\mathrm{A}$ and $\mathrm{B}$ were experimental groups and $\mathrm{C}$ was a control group. All patients on day 1 
learned two negatively valenced slide-show stories. Their memory for one of the two stories was reactivated 1 week later by presenting a partially covered slide of that story. Immediately after reactivation, patients in groups A and B went through ECT treatment; patients in group $\mathrm{C}$ did not. Group A patients were tested on a multiple choice memory quiz 1 day after the treatment, whereas group B patients were tested on the same quiz 90 minutes after the treatment. Group C patients had the same procedure as group A except for the ECT treatment. Results revealed that patients in group A showed significantly reduced memory accuracy for the reactivated story than for the non-reactivated one, suggesting that ECT disrupted the reconsolidation of the reactivated story. This effect was time-dependent in that patients in group B did not show memory impairment in the reactivated story because they were tested only 90 minutes after ECT, whereas group A patients were tested 1 day after ECT. Group C, the control group, showed an increase in memory accuracy of the reactivated story suggesting that without ECT disruption, reactivation was likely to enhance memory.

Though the two studies demonstrated that negative episodic memories could be impaired during reconsolidation, they also have limitations. First, they all used invasive agents (i.e., beta blocker and ECT). This limits the scope of their use because not only do they require the assistance of medical personnel, they also have various short-term and long-term side effects (Datto, 2000; Koller \& Vetere-Overfield, 1989). Second, the two studies did not test whether anxiety associated with negative episodic memories could be reduced during reconsolidation. Anxiety is a common response to fearful memories, and it is the hallmark of trauma-related disorders such as posttraumatic stress disorder (McNally, 2003). 
Accordingly, in this experiment I endeavored to replicate the findings of these recent studies, but without relying on propranolol or electroconvulsive therapy as the agents of reconsolidation disruption. In addition, I intended to explore whether anxiety associated with negative episodic memories could be reduced during reconsolidation. Anxiety reduction has not been tested in the reconsolidation of emotional episodic memories, though it has been extensively studied in the reconsolidation of conditioned fear memory (Agren et al., 2012; Kindt, Soeter, \& Vervliet, 2009; Schiller et al., 2010). In conditioned fear research, anxiety response to a specific stimulus is mediated by the amygdala; hence the key to attenuating anxiety is to update the representation of the fearful stimulus in the amygdala during reconsolidation (Agren et al., 2012; Schiller et al., 2010; Schiller, Kanen, LeDoux, Monfils, \& Phelps, 2013). However, in an episodic memory, there are likely many fearful stimuli in a given episode, hence anxiety response is not constrained to any specific stimulus, but is generalized to the context of the episode (Phelps, 2004).

Further compounding the complexity is the interaction between the amygdala and the hippocampus in forming and maintaining emotional episodic memories (Dolcos, LaBar, \& Cabeza, 2005; Phelps, 2004). During encoding, the amygdala releases norepinephrine to modulate the hippocampus and other cortical areas in formulating episodic representations (McGaugh, 2000, 2006). On the other hand, when recollecting emotional memories, the hippocampus becomes active which then triggers the emotional representations in the amygdala (Dolcos, Labar, \& Cabeza, 2005; LaBar \& Cabeza, 2006).

Given the constant interaction between the two structures in encoding and 
recalling, one way to reduce anxiety in emotional episodic memories is to target both amygdala- and hippocampus-mediated memories during reconsolidation. The current research design allows this approach. Specifically, a calming movie was introduced during reconsolidation to lower the arousal of consolidated negative episodic memories as well as to provide a new context for updating the episodic representations of the negative memories.

The experiment was conducted over three days. On Day 1, all participants viewed a stressful movie clip comprising scenes from the suspense film The Shining (Kubrick \& Kubrick, 1980), shown in a darkened laboratory testing room. Immediately thereafter, they recalled the movie and took a quiz on its details. On Day 2, participants were randomized to one of four groups (i.e., reminder/neutral, no reminder/neutral, reminder/positive, no reminder/positive). In the same darkened room, the reminder/neutral group viewed a brief segment from The Shining designed to reactivate the memory of the movie clip they saw the previous day prior to watching a calming, neutral clip from the documentary Baraka (Magidson \& Fricke, 1993), and the reminder/positive group viewed the same reminder from The Shining prior to watching an amusing clip from America's Funniest Home Videos (Di Bona, 1989). In a different, brightly lit testing room, the no reminder/neutral and the no reminder/positive groups watched only the neutral and positive films, respectively. On Day 3, all subjects underwent tests for memory accuracy, memory vividness, and memory anxiety associated with the stressful movie. I predicted that participants exposed to the neutral movie following reactivation of the memory of the stressful movie would exhibit decrements in memory accuracy, vividness, and anxiety for the stressful movie on Day 3, relative to the 
other groups. 


\section{Chapter II}

\section{Research Method}

\section{Participants}

Participants were recruited from Harvard undergraduate psychology classes via the Harvard Psychology Study Pool. To be eligible for the study, participants had to be between 18 and 65 years of age, fluent in English, and free of psychiatric or neurological disorders. Eighty-eight participants completed the study. Of these, 16 were excluded from data analyses: Four did not follow instructions; four were too scared to watch the stressful film and quit; five did not come back for either session 2 or 3; and three completed either session 2 or session 3 in less than 24 hours from the preceding session (instead of between 24 and 29 hours).

The final study sample consisted of 72 participants ( 44 women, 28 men) between the ages of 18 and $40(M=20.18, S D=3.49)$. Participants' ethnic backgrounds were Caucasian (47.2\%), Asian (31.9\%), Hispanic (9.7\%), Multi-racial (5.6\%), AfricanAmerican (4.2\%), and Arabic (1.4\%). Participants received course credit for their participation.

\section{Design}

I used a $2 \times 2$ between-subjects design with main factors of Reactivation (reminder, no reminder) and Movie (neutral, positive). There were four groups: (1) reminder/neutral movie; (2) no reminder/neutral movie; (3) reminder/positive movie; and (4) no reminder/positive movie. The dependent variables were three self-report 
measures: memory accuracy, memory vividness, and memory anxiety. The study was approved by the Harvard Committee on the Use of Human Subjects.

\section{Materials}

The experiment was programmed in OpenSesame, a free, cross-platform experiment builder (Mathot, Schreij, \& Theeuwes, 2012). It was administered via an HP Pavillion dv6 laptop computer.

\section{Movie Clip}

I used three movie clips of different emotional valence. They were stressful, neutral, and positive movie clips. The stressful movie clip was 20 minutes 22 seconds long and was taken from the movie, The Shining. The clip consisted of four scenes. The first two depict a child riding a tricycle in hallways in which he encounters the ghosts of two murdered girls. In the third scene, a woman tries to look at what her husband has been typing and is horrified by what she sees. The fourth scene depicts a man trying to kill his wife and child with an axe. The movie can elicit fear (Gross \& Levenson, 1995). During piloting, its valence and arousal ratings and standard deviations were $1.83 \pm 0.98$ and $6.5 \pm 0.55,(\mathrm{~N}=6)$. The ratings were on 1-7 Likert scales in which 1 denoted highly negative (valence) / highly calming (arousal), 4 denoted neutral (both valence and arousal), and 7 denoted highly positive (valence) / highly arousing (arousal).

The neutral movie clip was taken from the documentary, Baraka. It was 20 minutes 30 seconds long; it consisted of scenes depicting landscapes and people from around the globe. During piloting, its valence and arousal ratings and standard deviations 
were $4 \pm 0$ and $1.75 \pm 0.5,(N=4)$. The same Likert scales were used as in The Shining.

The positive movie clip was a compilation of humorous episodes from the TV program America's Funniest Home Videos. It was 20 minutes and 25 seconds long. During piloting, its valence and arousal ratings and standard deviations were $5.83 \pm 0.75$ and $4.83 \pm 0.98,(N=6)$.

\section{Movie Reminder}

In addition to the three movie clips, I used a reminder - an excerpt from the stressful movie clip. It was 1 minute and 30 seconds long. It consisted of snippets from the stressful movie clip, and was used to reactivate participants' memories of the stressful movie, i.e., participants who were assigned to the reactivation groups (reminder/neutral and reminder/positive). Moreover, it was edited in such a way as to leave an abrupt and suspenseful ending (i.e., the husband just breaks the bathroom door and is about to peek into it). The purpose was to create a mismatch between what was expected and what was actually seen. This reminder structure has been effective in triggering reconsolidation because it disrupts expectation (i.e., a mismatch; Lee, 2009, Coccoz, Maldonado, \& Delorenzi, 2011). Furthermore, for the two reactivation groups, after the reminder, a new movie (either neutral or positive) was presented after a 3-minute interval. Previous research found that amygdala-mediated, consolidated fear memory starts to destabilize 3 minutes after its reactivation (Monfils, Cowansage, Klann, \& LeDoux, 2009).

\section{Experiment Room and Lighting}

To facilitate memory reactivation for the reactivation groups as well as to prevent 
spontaneous memory reactivation by identical physical context for the no-reactivation groups (Hupbach, Hardt, Gomez, \& Nadel, 2008), I used two laboratory testing rooms. On Day 1, participants watched the stressful movie in the first room in a dark setting. This first, darkened room was also used on Day 2 for participants in the reactivation conditions. In contrast, another brightly-lit laboratory testing room was used on Day 2 for participants assigned to the no-reactivation conditions. This second, brightly-lit room was also used on Day 3 and for debriefing after the experiment.

\section{Memory Quiz}

I used two memory quizzes in the experiment. I gave the first quiz to participants on Day 1 after they watched the stressful movie. The purpose was to ensure that they actually watched the movie and encoded its contents. The first quiz contained 9 multiplechoice questions. The quiz instructions read: "There are 9 multiple-choice questions about the movie you just watched. Please choose the best answer for each question."

The questions were mainly about factual details such as: "Where does the woman put her tool of defense after she and the child get to the bathroom?" or "When the child sees the twin sisters in the hallway, what flashes before his eyes?"

The second quiz was administered on Day 3 to assess the effect of reconsolidation on memory accuracy. It contained 20 multiple-choice questions. The quiz instructions read: "There are 20 multiple-choice questions about the movie you watched on the first day of this experiment. Please choose the best answer for each question." Questions were also about factual details such as: "What does the woman use to defend herself in the bathroom when the man is trying to open the bathroom door?" or "What does the man 
say when he finds out that the woman is flipping through his typed pages on the desk?"

\section{Procedure}

The experiment was conducted in three consecutive days, 24-29 hours apart, to allow for memory consolidation and reconsolidation.

\section{Day 1 - Baseline Measure and Movie Encoding}

On day 1, participants read and signed 2 copies of the informed consent form, one of which was given to them, and the other was stored in a locked cabinet in the laboratory. They then provided information on age, gender, and ethnicity on a demographic questionnaire (Appendix A). They were then asked to turn to the computer screen, at which point the lights were switched off and the experimenter exited the room.

Participants first saw the following instructions on the computer screen: "In today's experiment, you will first rate your mood and then watch a movie. After the movie, you will complete some questionnaires. Please click NEXT when you are ready to begin." Participants were then presented with the instructions: "Please rate how you feel at this moment. Indicate your rating by clicking on 1 of the 7 boxes below. $1=$ very calm, 7 = very anxious. When you are done, press NEXT to proceed.” (Appendix B). Participants then viewed the stressful film on a laptop computer. Immediately thereafter, they were presented the following instructions: "Recall the movie you just watched. Bring it to mind as if you were watching it right now. In a moment, the screen will go blank for 30 seconds. While the screen is blank, please recall the movie as best as you can."

After a 30 -second pause, participants were asked to rate the vividness of their 
memory of the movie: "When recalling the movie, how vivid was your memory?

Indicate your rating by clicking on 1 of the 7 boxes below: $1=$ not vivid at all, $7=$ very vivid." After the vividness rating, they were asked to rate the anxiety prompted by the memory: "When recalling the movie, how anxious did the memory of the movie make you feel? Indicate your rating by clicking on 1 of the 7 boxes below: $1=$ not anxious at all, 7 = very anxious.” (Appendix C). Then, participants were asked whether they had seen this movie before: "Have you ever seen this movie before the experiment? $0=$ no, 1 = yes." (Appendix F).

After indicating their prior exposure to the stressful movie, participants were prompted to rate the valence and arousal of the movie. They were first instructed: "Please rate the valence of the movie, i.e., how positive or negative did the movie make you feel? 1 = highly negative, 4 = neutral, 7 = highly positive" and thereafter: "Please rate the arousal of the movie, i.e., how aroused did the movie make you feel? $1=$ highly calming, 4 = neutral (neither calming nor arousing), 7 = highly arousing." (Appendix D).

After the ratings, participants were given the first quiz to test their memory about the factual details of the movie (Appendix E). After the quiz, participants were thanked and reminded of the session the next day.

Day 2 - Memory Reactivation and Mood Induction

After Day 1's procedure, participants were randomly assigned to one of four experimental groups: reminder/neutral, no reminder/neutral, reminder/positive, no reminder/positive. These group assignments determined whether participants would first watch a reminder of the stressful movie as well as whether they would then watch a 
neutral or positive movie.

Reminder/ Neutral group. After seated in lab room 1 (same room as Day 1), participants were presented with the following instructions: "Today you will first watch an excerpt from yesterday's movie. Then you will watch a new movie and complete a set of questionnaires. Please click NEXT when you are ready to begin." Participants then viewed the reminder. Thereafter, they were instructed: "The movie excerpt has finished. Please relax for the next three minutes. The new movie will begin at that time." Then a white blank screen appeared and lasted for 3 minutes, after which the neutral movie was automatically played on the experimental laptop. After viewing the movie, participants were first asked to rate its valence: "Please rate the valence of the movie, i.e., how positive or negative did the movie make you feel? $1=$ highly negative, $4=$ neutral, $7=$ highly positive. Indicate your rating by clicking on 1 of the 7 boxes below." Immediately thereafter, they rated how arousing the movie was: "Please rate the arousal of the movie, i.e., how aroused did the movie make you feel? 1 = highly calming, $4=$ neutral (neither calming nor arousing), 7 = highly arousing. Indicate your rating by clicking on 1 of the 7 boxes below." They were then asked, "Approximately how many hours of sleep did you get last night? Indicate your rating by clicking on 1 of the 7 boxes below." The boxes were labeled, "less than 4," "4," "5," “6," "7," "8," and "more than 8." Participants were then thanked and reminded of the third session the following day. No Reminder/ Neutral group. Participants in this group completed Day 2's procedure in the brightly-lit lab room 2 to prevent spontaneous memory reactivation by context. After sitting down at the computer, they were presented with the following instructions:

"Today you will first watch a movie and then complete a set of questionnaires. Please 
click NEXT when you are ready to begin." Participants then proceeded to watch the neutral movie. Thereafter, they were first asked to rate its valence: "Please rate the valence of the movie, i.e., how positive or negative did the movie make you feel? $1=$ highly negative, $4=$ neutral, $7=$ highly positive. Indicate your rating by clicking on 1 of the 7 boxes below." Immediately thereafter, they rated how arousing the movie was: "Please rate the arousal of the movie, i.e., how aroused did the movie make you feel? $1=$ highly calming, $4=$ neutral (neither calming nor arousing), $7=$ highly arousing. Indicate your rating by clicking on 1 of the 7 boxes below." They were then asked, "Approximately how many hours of sleep did you get last night? Indicate your rating by clicking on 1 of the 7 boxes below." The boxes were labeled, "less than 4, , "4," "5," "6," "7," "8," and "more than 8." Participants were then thanked and reminded of the third session the following day.

Reminder/ Positive group. After seated in lab room 1 (same room as Day 1), participants were presented with the following instructions: "Today you will first watch an excerpt from yesterday's movie. Then you will watch a new movie and complete a set of questionnaires. Please click NEXT when you are ready to begin.” Participants then viewed the reminder. Thereafter, they were instructed: "The movie excerpt has finished. Please relax for the next three minutes. The new movie will begin at that time." Then a white blank screen appeared and lasted for 3 minutes, after which the positive movie was automatically played. After viewing the movie, participants were first asked to rate its valence: "Please rate the valence of the movie, i.e., how positive or negative did the movie make you feel? $1=$ highly negative, $4=$ neutral, $7=$ highly positive. Indicate your rating by clicking on 1 of the 7 boxes below." Immediately thereafter, they rated 
how arousing the movie was: "Please rate the arousal of the movie, i.e., how aroused did the movie make you feel? 1 = highly calming, 4 = neutral (neither calming nor arousing), 7 highly arousing. Indicate your rating by clicking on 1 of the 7 boxes below." They were then asked, "Approximately how many hours of sleep did you get last night? Indicate your rating by clicking on 1 of the 7 boxes below." The boxes were labeled, "less than 4," "4," "5," "6," "7," "8," and "more than 8." Participants were then thanked and reminded of the third session the following day.

No Reminder/ Positive group. Participants completed Day 2's procedure in the brightlylit lab room 2 to prevent spontaneous memory reactivation by context. After sitting down at the computer, they were presented with the following instructions: "Today you will first watch a movie and then complete a set of questionnaires. Please click NEXT when you are ready to begin." Participants then watched the positive movie. Thereafter, they were first asked to rate its valence: "Please rate the valence of the movie, i.e., how positive or negative did the movie make you feel $? 1=$ highly negative, $4=$ neutral, $7=$ highly positive. Indicate your rating by clicking on 1 of the 7 boxes below."

Immediately thereafter, they rated how arousing the movie was: "Please rate the arousal of the movie, i.e., how aroused did the movie make you feel? $1=$ highly calming, $4=$ neutral (neither calming nor arousing), $7=$ highly arousing. Indicate your rating by clicking on 1 of the 7 boxes below." They were then asked, "Approximately how many hours of sleep did you get last night? Indicate your rating by clicking on 1 of the 7 boxes below." The boxes were labeled, "less than 4," "4," "5," "6," "7," "8,, and "more than 8." Participants were then thanked and reminded of the third session the following day. 


\section{Day 3 - Testing Reconsolidation Effects}

After seated in lab room 2, all participants were presented with the following instructions: “In today’s experiment, you will complete some questionnaires. Please click NEXT when you are ready to begin." Thereafter, they were instructed: "Recall the stressful movie you watched on the first day of this experiment. Bring it to mind as if you were watching it right now. In a moment, the screen will go blank for 30 seconds. While the screen is blank, please recall the movie as best as you can." A white blank screen then appeared for 30 seconds, after which the following instructions appeared: "When recalling the stressful movie, how vivid was your memory? Indicate your rating by clicking on 1 of the 7 boxes below. $1=$ not vivid at all, $7=$ very vivid." Then, participants were presented with the next set of instructions: "When recalling the stressful movie, how anxious did the memory of the movie make you feel? Indicate your rating by clicking on 1 of the 7 boxes below. $1=$ not anxious at all, $7=$ very anxious." After the rating, participants were asked how many hours of sleep they had the night before. Next, participants were given a second memory quiz, which consisted of 20 multiple-choice questions. After the quiz, participants were debriefed about the experiment and then left. Below is a schematic illustration of the experimental procedure (Appendix G).

\section{Statistical Analysis}

Because I only began collecting self-reported hours of sleep beginning with the fourth participant, these data are missing for the first 3 participants (three data points for day 2, and three for day 3). I used the expectation maximization (EM) algorithm in SPSS to predict and re-populate the missing values. 

Day 1
$\stackrel{24-29 \mathrm{~h}}{\longrightarrow}$
Day 2
24-29 h
Day 3

- In experiment room 1
- Baseline anxiety rating
- Memory vividness, anxiety
ratings \#1
- Movie valence, arousal ratings
- Memory quiz \#1

Group 1: Video encoding

Group 2: Video encoding

Group 3: Video encoding

Group 4: Video encoding
- In experiment room 1 for the reminder groups

- In experiment room 2 for the no reminder groups

- Movie valence, arousal

ratings \#2

- Hours of sleep

Reminder $\longrightarrow$ 3-minute interval

$\rightarrow$ Neutral mood induction

No Reminder $\longrightarrow$ Neutral mood induction

Reminder $\longrightarrow$ 3-minute interval $\rightarrow$ Positive mood induction

No Reminder $\longrightarrow$ Positive mood induction
- In experiment room 2

- Vividness, anxiety ratings \#2

- Memory quiz \#2

- Hours of sleep

Reconsolidation effect

Reconsolidation effect

Reconsolidation effect

Reconsolidation effect

Figure 1. Experimental procedure.

\section{Retrospective Data}

One participant did not report her anxiety rating of the stressful movie on day 1 , and retrospectively reported the rating on day 2 .

\section{Outliers}

Outliers in the study were defined as any data point that was more than 3 times the interquartile range. To test their influence on measures with outliers, I reported analyses both with and without the outliers.

\section{Day 1 Measures}

I used one-way analyses of variance (ANOVAs) of group (reminder/neutral, no 
reminder/neutral, reminder/positive, no reminder/positive) for the following variables: age, baseline feeling, memory vividness, memory anxiety, memory accuracy (as percentage correct), stressful movie's valence and arousal ratings. In addition, I tested group differences in gender, ethnicity, and whether participants had seen the movie before the experiment via chi-square tests for association.

\section{Day 2 Measures}

To test between group differences in valence and arousal of both the neutral and positive movies, I conducted four independent-samples $t$-tests (i.e., reminder/neutral vs. no reminder/neutral in valence and arousal, and reminder/positive vs. no reminder/positive in valence and arousal).

Also, to assess whether mood induction was successful on day 2, I conducted four paired-samples $t$-tests to assess the differences in valence and arousal ratings between the stressful movie and the neutral movie, as well as between the stressful movie and the positive movie.

I also tested group differences in hours of sleep via a one-way ANOVA with a main effect of group.

\section{Day 3 Measures}

I tested for reconsolidation effects on memory accuracy, memory vividness, and memory anxiety by using two-way ANOVAs with main effects of Reactivation (reminder, no reminder) and Movie (neutral, positive). When significant interactions occurred, I conducted tests for simple main effects of reactivation and of movie, and I 
used the Bonferroni procedure to adjust the alpha level to $p<.025$.

I tested group differences in hours of sleep via a one-way ANOVA with a main effect of group.

\section{Exploratory Tests}

I conducted an additional two-way ANOVA to test if anxiety reduced during reconsolidation for participants who reported high level anxiety on Day 1 (i.e., anxiety scores between 5 and 7).

In addition, to determine whether the reported measures differed significantly between Day 1 and Day 3, I conducted mixed three-way ANOVAs of Day (day 1, day 3), Reactivation (reminder, no reminder), and Movie (neutral, positive) for memory accuracy, memory vividness, and memory anxiety. 


\section{Chapter III}

Results

I predicted and re-populated the six missing values on sleep hour using the expectation maximization (EM) algorithm from SPSS. Before running the algorithm, I tested the assumption with a Little's Missing Completely at Random test. The results showed that the values were missing at random $\chi^{2}=13.57(\mathrm{df}=8, \mathrm{p}<.094)$, i.e., the assumption of the EM technique was met.

\section{Day 1 - Baseline Measure and Movie Encoding}

The 4 groups did not differ significantly in gender, $\chi^{2}(3, \mathrm{~N}=72)=1.40, p=.71$, ethnicity, $\chi^{2}(15, \mathrm{~N}=72)=13.24, p=.58$, or age, both when the outliers were included, $F(3,68)=0.94, p=.42$, as well as when they were excluded, $F(3,65)=1.30, p=.28$. Additionally, they did not significantly differ in baseline feeling, $F(3,68)=0.67, p=.58$, $\eta_{\mathrm{p}}^{2}=.03$, memory anxiety, $F(3,68)=0.41, p=.74, \eta_{\mathrm{p}}^{2}=.02$, memory vividness, both when the outliers were included, $F(3,68)=1.02, p=.39, \eta_{\mathrm{p}}^{2}=.04$, as well as when they were excluded, $F(3,66)=2.20, p=.10, \eta_{\mathrm{p}}^{2}=.09$.

Also, they did not differ significantly in memory accuracy, both when the outliers were included, $F(3,68)=0.41, p=.74, \eta_{\mathrm{p}}^{2}=.02$, as well as when they were excluded, $F(3,64)=2.35, p=.08, \eta_{\mathrm{p}}^{2}=.10$. Furthermore, the groups did not differ significantly in the number of people who had seen the stressful movie before the experiment, $\chi^{2}(3, \mathrm{~N}=$ $72)=4.54, p=.21$. Table 1 summarizes the baseline measures. 
Table 1

Means and Standard Deviations of Day 1's Measures

\begin{tabular}{lcccccccc}
\hline & \multicolumn{2}{c}{$\begin{array}{c}\text { Re+Neutral } \\
(n=18)\end{array}$} & \multicolumn{2}{c}{$\begin{array}{c}\text { NoRe+Neutral } \\
(n=18)\end{array}$} & $\begin{array}{c}\text { Re+Positive } \\
(n=18)\end{array}$ & $\begin{array}{c}\text { NoRe+Positive } \\
(n=18)\end{array}$ \\
\hline Variable & $M$ & $S D$ & $M$ & $S D$ & $M$ & $S D$ & $M$ & $S D$ \\
\hline Baseline Feel & 2.50 & 1.20 & 3.06 & 1.11 & 2.83 & 1.20 & 2.83 & 1.25 \\
Vividness & 5.39 & 0.61 & 5.67 & 0.77 & 5.89 & 0.90 & 5.78 & 1.22 \\
Anxiety & 4.56 & 1.29 & 4.17 & 2.36 & 4.17 & 1.20 & 4.67 & 1.78 \\
Accuracy & $96 \%$ & $8 \%$ & $96 \%$ & $8 \%$ & $94 \%$ & $8 \%$ & $96 \%$ & $7 \%$ \\
Age & 20.17 & 3.43 & 19.28 & 1.02 & 20.06 & 3.11 & 21.22 & 5.12 \\
\hline & $Y e s$ & $N o$ & $Y e s$ & $N o$ & $Y e s$ & $N o$ & $Y e s$ & $N o$ \\
\hline Seen Before & 1 & 17 & 5 & 13 & 6 & 12 & 5 & 13 \\
\hline
\end{tabular}

Note. Baseline feel ratings were on the scale of 1 to 7 , with 1 being very calm, 7 being very anxious. Memory vividness and anxiety ratings were on the scale of 1 to 7 , with 1 being not at all vivid / not at all anxious, 7 being very vivid / very anxious.

Movie Rating Check

After watching the stressful movie, the groups did not differ in their ratings of valence (i.e., positive vs. negative), $F(3,68)=1.04, p=.38, \eta_{\mathrm{p}}^{2}=.04$, and arousal (i.e., calming vs. arousing), both when an outlier was included, $F(3,68)=1.18, p=.33, \eta_{\mathrm{p}}^{2}=$ .05 , as well as when it was excluded, $F(3,67)=2.06, p=.11, \eta_{\mathrm{p}}^{2}=.08$. Table 2 summarizes the movie ratings.

\section{Day 2 - Memory Reactivation and Mood Induction}

Participants were randomly assigned to 4 experimental groups: reminder/neutral, no reminder/neutral, reminder/positive, no reminder/positive. Participants who were assigned to the reminder groups first watched a 30-second clip of the stressful movie 
Table 2

Means and Standard Deviations of the Valence and Arousal Ratings of the Stressful Movie

\begin{tabular}{lcccccccc}
\hline & \multicolumn{2}{c}{$\begin{array}{c}\text { Re+Neutral } \\
(n=18)\end{array}$} & \multicolumn{2}{c}{$\begin{array}{c}\text { NoRe+Neutral } \\
(n=18)\end{array}$} & \multicolumn{2}{c}{$\begin{array}{c}\text { Re+Positive } \\
(n=18)\end{array}$} & $\begin{array}{c}\text { NoRe+Positive } \\
(n=18)\end{array}$ \\
\hline Variable & $M$ & $S D$ & $M$ & $S D$ & $M$ & $S D$ & $M$ & $S D$ \\
\hline StressfulMovie Valence & 2.39 & 1.09 & 2.61 & 1.29 & 2.28 & 0.89 & 2.00 & 0.91 \\
StressfulMovie Arousal & 5.44 & 1.04 & 5.83 & 0.99 & 5.89 & 1.18 & 6.06 & 0.80 \\
\hline
\end{tabular}

Note. Valence and arousal ratings were on the scale of 1 to 7 , with 1 being the most negative / most calming, 7 being the most positive / most arousing. before they watched either a neutral or a positive movie. Participants who were assigned to the no reminder groups watched only a neutral film or a positive film.

The two groups that watched the neutral movie did not differ significantly in their ratings of valence, $t(34)=1.20, p=.24, d=0.40$, or arousal, $t(34)=1.70, p=.10, d=$ 0.57. Similarly, the two groups that watched the positive movie did not differ significantly in their ratings of valence, $t(34)=0.20, p=.85, d=0.07$, or arousal, $t(34)=$ $0.17, p=.91, d=0.04$

The 4 groups also did not differ significantly in hours of sleep for the preceding night, $F(3,68)=0.44, p=.73, \eta_{\mathrm{p}}^{2}=.02$.

\section{Mood Induction}

Participants' ratings on the neutral and positive movies suggested that mood induction was successful. The neutral movie's valence and arousal ratings and standard deviations were $4.61 \pm 0.84$ and $1.97 \pm 1.11$, respectively. The positive movie's valence 
and arousal ratings and standard deviations were $6.03 \pm 0.84$, and $3.92 \pm 1.42$, respectively.

Moreover, to assess whether these valence and arousal ratings were significantly different from those of the stressful movie, I conducted 4 paired-samples $t$-tests, i.e., neutral movie groups' valence and arousal ratings for the neutral and stressful movies, and positive movie groups' valence and arousal ratings for the positive and stressful movies.

Participants in the neutral groups rated the neutral movie as significantly more positive than the stressful movie, $t(35)=7.83, p<.001, d=1.31$, and significantly less arousing than the stressful movie, $t(35)=14.93, p<.001, d=2.49$. Similarly, participants in the positive groups rated the positive movie as significantly more positive than the stressful movie, $t(35)=19.23, p<.001, d=3.20$, and significantly less arousing than the stressful movie, $t(35)=7.03, p<.001, d=1.17$. Table 3 and Table 4 summarize the results.

\section{Day 3 - Testing Reconsolidation Effects}

I conducted three two-way ANOVAs to assess the reconsolidation effects of memory accuracy, memory vividness, and memory anxiety. Additionally, I conducted a one-way ANOVA to examine group difference in hours of sleep for the preceding night.

Moreover, in exploratory tests, I conducted a two-way ANOVA to test if anxiety was reduced during reconsolidation for participants who reported high level anxiety on day 1 (i.e., between 5 and 7). I also conducted three mixed 3-way ANOVAs to examine the differences of the reported measures between Day 1 and Day 3. 
Table 3

Contrasts of Neutral Movie Groups' Valence and Arousal Ratings for the Neutral Movie with Their Valence and Arousal Ratings for the Stressful Movie

\begin{tabular}{lcccccccc}
\hline & \multicolumn{3}{c}{ Neutral Movie Groups } & & \multicolumn{2}{c}{$95 \% \mathrm{CI}$} & \\
\cline { 2 - 4 } Variable & $M$ & $S D$ & $t(35)$ & $p$ & & $L L$ & $U L$ & Cohen's $d$ \\
\hline Neutral Movie Valence & 4.61 & 0.84 & & 7.83 & $<.001$ & 1.56 & 2.66 & 1.31 \\
Stressful Movie Valence & 2.5 & 1.18 & & & & & \\
\hline Neutral Movie Arousal & 1.97 & 1.11 & -14.93 & $<.001$ & -4.17 & -3.17 & 2.49 \\
Stressful Movie Arousal & 5.64 & 1.02 & & & & & \\
\hline
\end{tabular}

Note. $\mathrm{CI}=$ confidence interval; $L L=$ lower limit; $U L=$ upper limit.

Table 4

Contrasts of Positive Movie Groups' Valence and Arousal Ratings for the Positive Movie with Their Valence and Arousal Ratings for the Stressful Movie

\begin{tabular}{|c|c|c|c|c|c|c|c|}
\hline \multirow[b]{2}{*}{ Variable } & \multicolumn{4}{|c|}{ Positive Movie Groups } & \multicolumn{3}{|c|}{$95 \% \mathrm{CI}$} \\
\hline & $M$ & $S D$ & $t(35)$ & $p$ & $\overline{L L}$ & $U L$ & Cohen's $d$ \\
\hline Positive Movie Valence & 6.03 & 0.84 & 923 & 01 & 348 & 430 & 320 \\
\hline Stressful Movie Valence & 2.14 & 0.90 & & & & & \\
\hline Positive Movie Arousal & 3.92 & 1.42 & 703 & & -265 & 146 & 11 \\
\hline Stressful Movie Arousal & 5.97 & 1.00 & & & & & \\
\hline
\end{tabular}

Note. $\mathrm{CI}=$ confidence interval; $L L=$ lower limit; $U L=$ upper limit.

\section{Memory Accuracy}

I hypothesized that participants who watched the reminder and then the neutral movie would remember fewer details of the stressful movie than would participants in the other groups. The results supported this hypothesis. There was a significant interaction between reactivation and movie, $F(1,68)=7.32 p=.01, \eta^{2}=.10$. Therefore, I 
performed two simple main effects analyses (i.e., for reactivation and for movie), and I also Bonferroni-adjusted the statistical significance level to $p<.025$.

As indicated by a significant simple main effect of reactivation, $F(1,68)=10.68$, $p=.002, \eta_{\mathrm{p}}^{2}=.14$, participants who viewed the reminder before watching the neutral film subsequently recalled fewer details from the stressful film than did subjects who did not view the reminder before watching the neutral movie (Figure 2). However, the simple main effect of reactivation was not significant for those who watched the positive movie: Those who viewed the reminder did not differ in the number of details they recalled from the stressful movie than did those who did not view the reminder, $F(1,68)$ $=0.31, p=.58, \eta_{\mathrm{p}}^{2}=.01$ (Figure 2).

The simple main effect of movie was non-significant for participants who viewed the reminder. Participants who watched the positive movie did not differ in memory accuracy from those who watched the neutral movie, $F(1,68)=4.30, p=.04, \eta^{2}=.06$ (Figure 2). In addition, the simple main effect of movie was also non-significant for participants who did not view the reminder. Those who watched the positive movie did not differ from those who watched the neutral movie in the number of details they could recall from the stressful movie, $F(1,68)=3.08, p=.08, \eta_{\mathrm{p}}^{2}=.04$ (Figure 2).

Given the significant simple main effect of reactivation, I conducted a pair-wise comparison for the reminder/neutral vs. no reminder/neutral groups. The mean memory accuracy scores were $0.77(S D=.093)$ and $0.88(S D=.075)$ for the reminder/neutral and no reminder/neutral groups: Participants who watched the reminder recalled 11 percent fewer details of the stressful movie than those who did not watch the reminder $(95 \% \mathrm{CI}$, .183 to -.044$), p=.002$. 


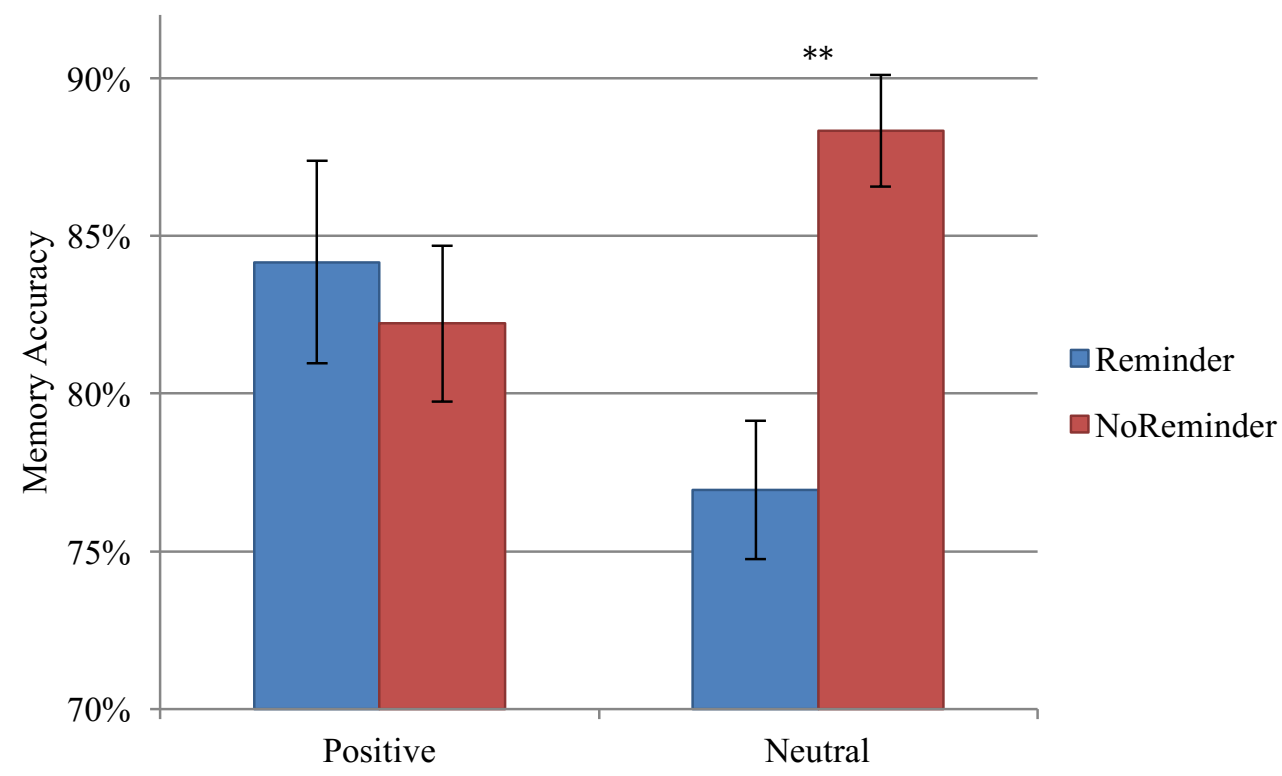

Figure 2. Reconsolidation Effect of Memory Accuracy. There is a statistically significant interaction between Reactivation (reminder, no reminder) and Movie (positive, neutral). It was driven by the neutral/reminder group remembering significantly fewer details than the no reminder/neutral group. The error bars represent the standard error of the mean. $* * p<.01$

\section{Memory Vividness}

I hypothesized that participants who watched the reminder and then the neutral movie would remember the stressful movie less vividly than participants in the other groups. The results did not support this hypothesis. There was no statistically significant interaction between reactivation and movie for memory vividness, $F(1,68)=0.22, p=$ $.64, \eta_{\mathrm{p}}^{2}=.00$. There were also no statistically significant main effects of either reactivation, $F(1,68)=0.22, p=.64, \eta_{\mathrm{p}}^{2}=.00$, or movie, $F(1,68)=1.19, p=.28, \eta_{\mathrm{p}}^{2}=$ .02 (Figure 3). 


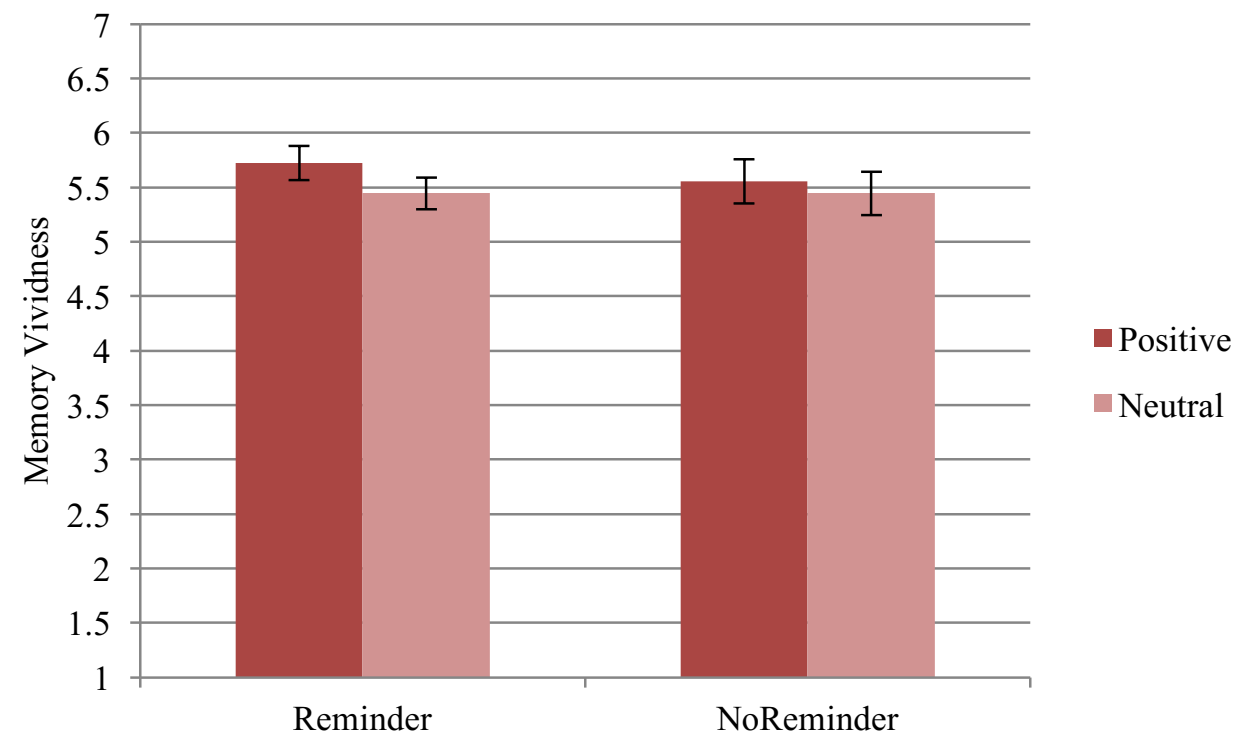

Figure 3. Reconsolidation Effect of Memory Vividness. There is no statistically significant interaction between Reactivation (reminder, no reminder) and Movie (positive, neutral). There are also no significant main effects of either Reactivation or Movie. The error bars represent the standard error of the mean.

\section{Memory Anxiety}

I hypothesized that participants who watched the reminder and then the neutral movie would show lowered memory anxiety than participants in the other groups. The results did not support this hypothesis. There was no statistically significant interaction between reactivation and movie for memory anxiety, $F(1,68)=0.11, p=.74, \eta_{p}^{2}=.00$. There were also no statistically significant main effects of either reactivation, $F(1,68)=$ $0.70, p=.41, \eta_{\mathrm{p}}^{2}=.01$, or movie, $F(1,68)=0.03, p=.87, \eta_{\mathrm{p}}^{2}=.00$ (Figure 4). 


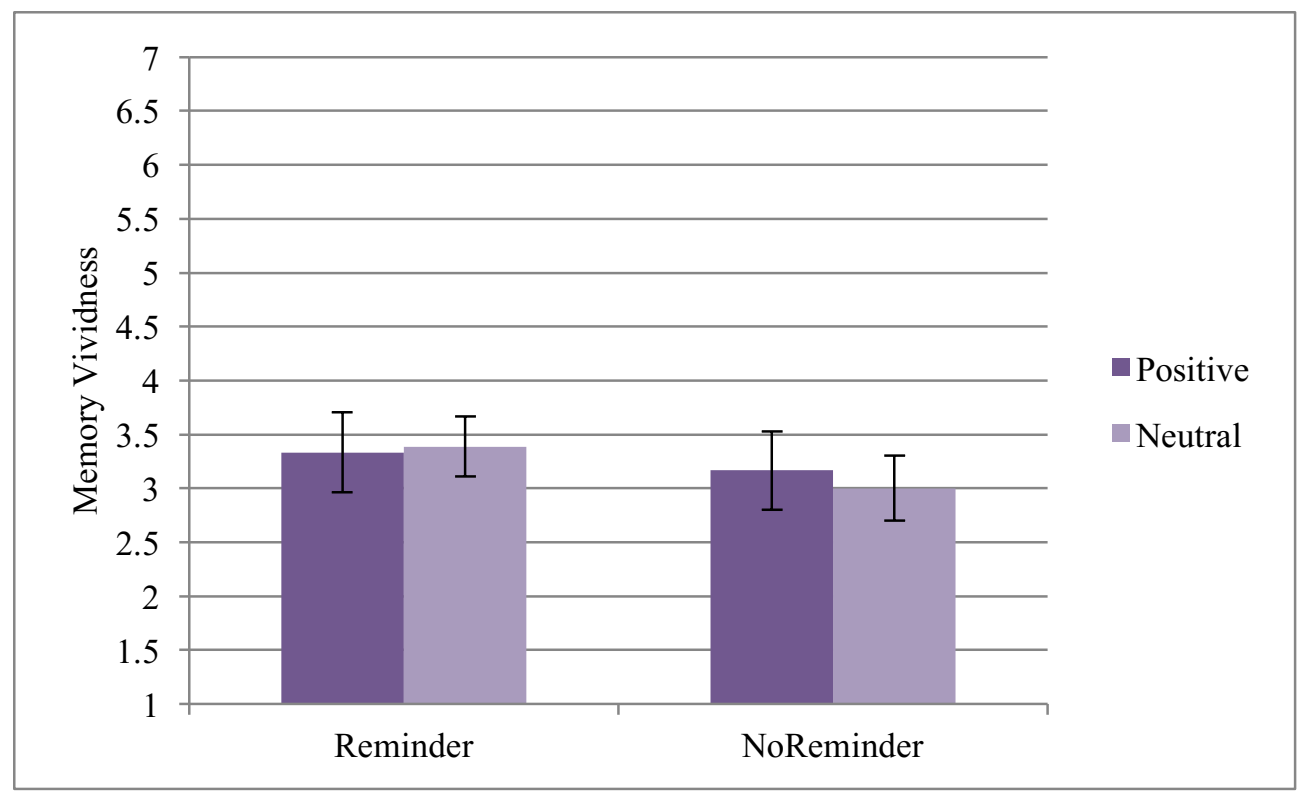

Figure 4. Reconsolidation Effect of Memory Anxiety. There is no statistically significant interaction between Reactivation (reminder, no reminder) and Movie (positive, neutral). There are also no significant main effects of either Reactivation or Movie. The error bars represent the standard error of the mean.

Sleep Hour

Means and standard deviations of sleep hours for the four groups (reminder/neutral, no reminder/neutral, reminder/positive, no reminder/positive) were $6.69 \pm 1.11$, and $6.59 \pm 1.28,6.17 \pm 1.34,6.94 \pm 1.06$. There was no significant difference, $F(3,68)=1.31, p=.28, \eta_{\mathrm{p}}^{2}=.05$.

\section{Exploratory Tests}

I conducted a two-way ANOVA to examine the reconsolidation effect for participants who reported high level anxiety on Day 1 (scores between 5 and 7). After removing participants who reported below 5, the reminder/neutral group had 12 
participants left, the no reminder/neutral group had 10, the reminder/positive group had 9 , and the no reminder/positive group had 11 participants.

Results revealed that there was no statistically significant interaction between reactivation and movie for memory anxiety, $F(1,38)=0.01, p=.92, \eta_{\mathrm{p}}^{2}=.00$. There were also no statistically significant main effects of either reactivation, $F(1,38)=0.15, p$ $=.70, \eta_{\mathrm{p}}^{2}=.00$, or movie, $F(1,38)=0.72, p=.40, \eta_{\mathrm{p}}^{2}=.02$.

Mixed 3-way ANOVAs. I tested the differences of reported measures for memory accuracy, vividness, and anxiety between Day 1 and Day 3 with mixed 3-way ANOVAs. For memory accuracy, there was a statistically significant three-way interaction between Day (day 1, day 3), Reactivation (reminder, no reminder), and Movie (neutral, positive), $F(1,68)=8.67, p=.004, \eta_{\mathrm{p}}^{2}=.11$. To clarify this interaction, I conducted two simple two-way analyses and found a statistically significant simple two-way interaction of Reactivation and Movie for Day $3, F(1,68)=7.32, p=.009$, but not for Day $1, F(1,68)$ $=0.26, p=.61$. Probing this effect further, I found a significant simple simple main effect of Reactivation for the neutral movie, $F(1,68)=10.68, p=.002$, but not for the positive one, $F(1,68)=0.31, p=.58$. This result suggested that the three-way interaction was driven by the reminder/neutral group remembering significantly fewer details about the stressful movie on Day 3.

For memory vividness, there was no statistically significant three-way interaction of Day, Reactivation, and Movie, $F(1,68)=0.25, p=.62, \eta_{\mathrm{p}}^{2}=.00$. There were also no significant two-way interactions, all $p \mathrm{~s}>.39$.

For memory anxiety, there was no statistically significant three-way interaction, $F(1,68)=0.81, p=.37, \eta_{\mathrm{p}}^{2}=.01$. There were also no statistically significant two-way 
interactions, all $p \mathrm{~s}>.37$. However, there was a significant main effect of Day $F(1,68)=$ $39.67, p<.001, \eta_{\mathrm{p}}^{2}=.37$, suggesting that participants' anxiety scores were different between Day 1 and Day 3.

Because the four groups did not differ significantly in anxiety rating both on Day $1, F(3,68)=0.41, p=.74$, and Day $3, F(3,68)=0.28, p=.84$, I treated Day 1 and Day 3's ratings as two group ratings, and conducted a paired-samples $t$-test to test the difference. Result showed a significant difference between the two groups: Participants reported $4.39(S D=1.70)$ on Day 1, and $3.22(S D=1.39)$ on Day 3, a significant decrease of $1.17, t(71)=6.36, p<.001, d=0.75,95 \% \mathrm{CI}[0.80,1.53]$. 


\section{Chapter IV}

Discussion

In this study, I investigated the reconsolidation of negative episodic memories. Specifically, I studied whether memory accuracy, memory vividness, and memory anxiety could be reduced during reconsolidation via neutral mood induction. I hypothesized that memory accuracy, memory vividness, and memory anxiety would be reduced during reconsolidation via neutral mood induction.

The first hypothesis was confirmed, i.e., memory accuracy decreased by 11 percent in participants who first reactivated their memories of the stressful movie and then watched the neutral, calming movie. The result replicated findings from other studies on the reconsolidation of emotional episodic memories that used B-blockers or electroconvulsive therapy (Kroes et al., 2014; Schwabe et al., 2013). The accuracy reduction is likely due to a reduction in arousal during reconsolidation. Arousal enhances memory encoding and leads to more accurate memories about contextual details (e.g., spatio-temporal, perceptual; Kensinger \& Schacter 2008; McGaugh, 2006). Hence, lowering arousal would reduce its enhancing effect on memory accuracy for details (Schwabe et al., 2013). The result is strong, especially considering that memory for movies is fairly robust, accurate, and its accuracy persists for months (Furman, Dorfman, Hasson, Davachi, \& Dudai, 2007).

The second hypothesis was not confirmed, i.e., memory vividness did not decrease during reconsolidation for participants who viewed the reminder and then the calming movie. There was no difference in reported vividness among the four 
groups. The result was not consistent with Schwabe et al. (2013) that vividness was reduced for participants who took propranolol before memory reactivation. The result is somewhat surprising because there is compelling evidence that vividness is mainly driven by arousal (Kensinger \& Schacter, 2008; McGaugh, 2006; Phelps, 2004). Hence, if arousal diminished during reconsolidation, vividness should have declined, too.

Several explanations may account for the result. First, unlike the ß-blocker propranolol, the calming movie was not as potent to dampen vividness during reconsolidation. The movie was only 20 minutes long: Its effect was transient and wore off quickly. But the effect of propranolol lasts for hours: Plasma concentration of orally consumed propranolol reduces to half its original value in 6 hours (Nies \& Shand, 1975). Therefore, it could be that during reconsolidation, propranolol continued to dampen arousal, which contributed to reduced vividness (Schwabe et al., 2013).

Second, it could be due to the way memory vividness was examined. It was examined by the question: "when recalling the movie, how vivid was your memory?" Although participants reported high vividness, the nature of the vividness was ambiguous. For example, it could be that they remembered specific perceptual or contextual details vividly, or it could be that they were biased to report high vividness because the experience was emotional, especially considering that emotional experiences can lead to an inflated sense of vividness (Kensinger \& Schacter, 2008; Sharot, Delgado, \& Phelps, 2004).

One way to correct the potential bias is to use a more specific and objective measure for vividness. The 2-step procedure known as the "old"/"new," "remember"/"know," procedure is ideal (Eldridge, Sarfatti, \& Knowlton, 2002; Schwabe 
et al., 2013). In this procedure, participants are first asked to indicate whether they have previously encountered a stimulus (e.g., a picture). If they selected yes, then they would be asked whether they could recall its occurrence with vivid contextual details (i.e., "remember"), or without any contextual details (i.e., "know"). Hence, the procedure allows for a more specific test of vividness.

In addition, the procedure also allows for a more objective test of vividness: It does not ask participants to reflect on an experience as a whole (e.g., recall the stressful movie), but rather asks participants to respond to specific stimuli within the experience. In the context of this study, participants would first be asked whether they recognize a given screenshot from the stressful movie, and if they recognized the screenshot, they would then be asked whether they could vividly recall it (i.e., "remember") or they could only remember that it happened (i.e., "know").

The third hypothesis was not confirmed, i.e., memory anxiety associated with the negative emotional memories was not reduced during reconsolidation. Although the study design targeted both the amygdala-mediated (i.e., emotional representations) and hippocampus-mediated memories (i.e., episodic representations), anxiety was still not reduced. There could be several reasons.

First, it could be that the negative memories were not fully consolidated and hence could not be reconsolidated or modified during reconsolidation. This was unlikely for two reasons. First, the study revealed a reconsolidation effect on memory accuracy. Second, studies that used this 3-day procedure with 24-hour intervals showed reconsolidation effect in both nondeclarative conditioned fear memory (Kindt \& Soeter, 2013; Schiller et al., 2013) and declarative episodic memory (Schwabe et al., 2013; 
Schwabe, Nader, Wolf, Beaudry, \& Pruessner, 2012).

Second, it could be that the strength of the new episodic encoding was so weak that it was insufficiently potent to modify the existing episodic representations. Previous research showed that weaker new learning after reactivation (i.e., learning new photos 1 time) did not disrupt the original memory as much as stronger new learning (i.e., learning new photos 3 times) (Wichert, Wolf, \& Schwabe., 2013). In the context of this study, it could be that the duration of the calming movie was short, i.e., the new episodic learning was weak. Hence, one way to test it would be to prolong the calming movie from 20 minutes to 40 or 60 minutes.

Third, it could be that the context of the calming movie did not match the context of the stressful movie. In other words, the context of the calming movie was irrelevant to the context of the stressful movie such that the episodic representations of the stressful movie were not updated. The stressful movie consisted mostly of scenes in which people were acting and conversing and it did not contain natural landscapes. In contrast, the calming movie consisted mostly of natural landscapes and was devoid of human interaction (i.e., no narration).

Hence, one way to remedy this is to match the contexts between the calming movie and the stressful movie while controlling for arousal. A neutral movie with the main characters from the stressful movie is likely to suffice.

In addition to the planned tests, I did several exploratory tests. First, I tested whether there was a reconsolidation effect on memory anxiety for participants who reported high anxiety scores on Day 1 (i.e., between 5 and 7). The result showed no reconsolidation effect for this subgroup - it concurred with the overall result. 
Moreover, I conducted several mixed 3-way ANOVAs to test for differences in the measures between Day 1 and Day 3 (i.e., memory accuracy, memory vividness, and memory anxiety). For memory accuracy, I found a significant three-way interaction. It was driven by the reminder/neutral group remembering significantly fewer details of the stressful movie on Day 3. This result corroborated the finding that memory accuracy for the reminder/neutral group was reduced during reconsolidation.

For memory vividness, I did not find any three-way or two-way interactions. This was consistent with the finding that there was no reconsolidation effect for memory vividness.

For memory anxiety, I did not find any statistically significant three-way or twoway interaction. However, I found a significant main effect of Day such that participants were significantly less anxious on Day 3 compared to Day 1 . The result could reflect a general decline of memory anxiety over time (i.e., 48 hours).

The results of the study raise a concern relevant to memory reconsolidation in clinical settings to treat trauma-related disorders. The hallmarks of such disorders are intrusive memories coupled with vivid imagery and intense anxiety (McNally, 2003). An effective treatment should reduce vividness and anxiety while preserving memories so that patients are able to recall them with ease and tranquility. Results of this study, however, suggest a reverse pattern — participants could recall the memories just as vividly (though not as anxiously), but could not recall the details as accurately. Hence, more research is needed to elucidate the mechanisms of the reconsolidation of vividness and anxiety of emotional episodic memories.

The study has several limitations. First, the study only used undergraduate 
college students as participants. As such, it is difficult to argue to what extent the experimental results can be generalized to other populations, especially clinical ones. However, since the experimental paradigm is rather new, it is safer to first test it on a normal population.

Another concern regards the stimuli. The study used movie clips as stimuli. Although movies mimic the dynamic and contextualized nature of episodic memories (Furman et al., 2007), they are still not real-life episodes. Therefore, people may have different emotional and cognitive reactions toward these two kinds of stimuli. As such, it is difficult to predict to what extent the study results are translatable to real-life events. On the other hand, however, using movie clips confers an advantage of controlling and standardizing stimuli across participants as memories of everyday events are variable and not standardized (Furman et al., 2007).

An additional concern is the duration of the study. The study was conducted in three consecutive days. This design has satisfied the requirements for testing reconsolidation effects as it allows enough time for memories to fully consolidate before testing (Agren, 2014), but it cannot test long-term memories that are more than two days old. Future studies need to substantiate the findings by using longer intervals (e.g., 7 days).

Another limitation concerns research design. The study did not include a nointervention group on Day 2 and therefore cannot rule out the possibility that doing nothing (e.g., no reminder, no movie) could have produced the same results. Though it is possible for memory vividness and anxiety (since they did not change), it is unlikely for memory accuracy. As noted in Furman et al. (2007), memory retention for movie details 
in the first week is about $88 \%$. It corresponds to the results of the groups that showed no reconsolidation effect (i.e., reminder/positive, no reminder/positive, and no reminder/neutral). But the accuracy for the reminder/neutral group was about $77 \%$, hence suggesting an occurrence of reconsolidation disruption.

Finally, the study did not ask all participants to watch and rate all movies, i.e., participants in the positive movie groups did not watch and rate the neutral movie and vice versa. As such, it is not possible to know whether arousal was different between the positive and neutral movies. However, because the groups did not differ in their ratings of the stressful movie, and, respectively, the positive and neutral movie groups did not differ in their ratings of the positive and neutral movies, it is reasonable to assume that they would not have differed in their ratings of each other's movies had they watched them, i.e., the positive movie groups would not have differed from the neutral movie groups in the neutral movie ratings and vice versa.

The study has implications for research in the reconsolidation of negative episodic memories. It is the first study that used movies and found memory accuracy reduction during reconsolidation of negative episodic memories. This replicated the findings of previous studies, without relying on propranolol (Schwabe et al., 2013) or ECT (Kroes et al., 2014). Additionally, because the study attempted to reduce the memory-enhancing effect of negative emotions, its results could have potential implications for treating anxiety disorders such as post-traumatic stress disorder (PTSD). 
Appendix A

Demographic Information Form

Subject ID:

Age:

Sex:

Ethnicity: 


\section{Appendix B}

Baseline Mood Rating Scale

Please rate how you feel at this moment. Indicate your rating by clicking on 1 of the 7 boxes below. $1=$ very calm, $7=$ very anxious.

very calm very anxious

\begin{tabular}{lllllll}
\hline & 2 & 3 & 4 & 5 & 6 & 7
\end{tabular}




\section{Appendix C}

Memory Vividness and Anxiety Rating Scales

Recall the stressful movie you just watched / watched on the first day of the experiment. Bring it to mind as if you were watching it right now. In a moment, the screen will go blank for 30 seconds. While the screen is blank, please recall the movie as best as you can.

Memory Vividness Rating Scale

When recalling the movie, how vivid was your memory? Indicate your rating by clicking on 1 of the 7 boxes below. $1=$ not at all vivid, $7=$ very vivid

not vivid at all

very vivid

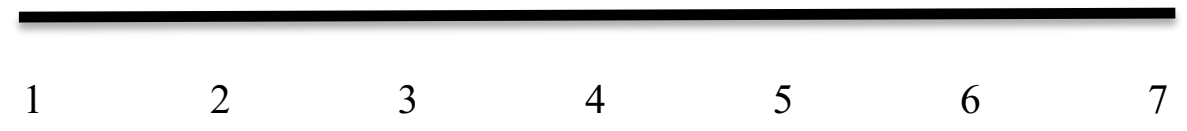

Memory Anxiety Rating Scale

When recalling the movie, how anxious did the memory of the movie make you feel? Indicate your rating by clicking on 1 of the 7 boxes below. $1=$ not at all anxious, 7 = very anxious

not anxious at all very anxious

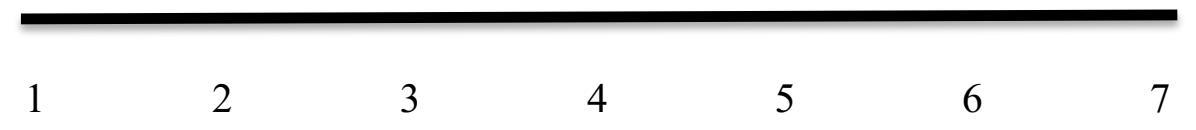




\section{Appendix D}

\section{Movie Valence and Arousal Rating Scales}

Movie Valence Rating Scale

Please rate the valence of the movie, i.e., how positive or negative did the movie make you feel? 1 = highly negative, $4=$ neutral, 7 = highly positive. Indicate your rating by clicking on 1 of the 7 boxes below. When you are done, press NEXT to proceed.

highly negative

highly positive

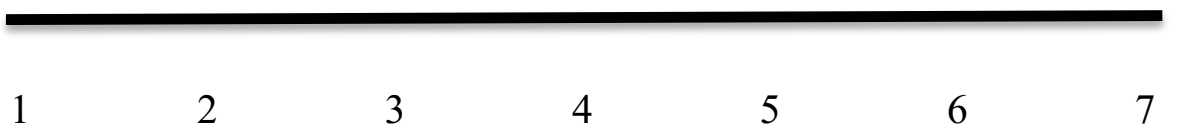

Movie Arousal Rating Scale

Please rate the arousal of the movie, i.e., how aroused did the movie make you feel? 1 = highly calming, 4 = neutral (neither calming nor arousing), 7 = highly arousing. Indicate your rating by clicking on 1 of the 7 boxes below. When you are done, press NEXT to proceed.

not arousing at all

highly arousing

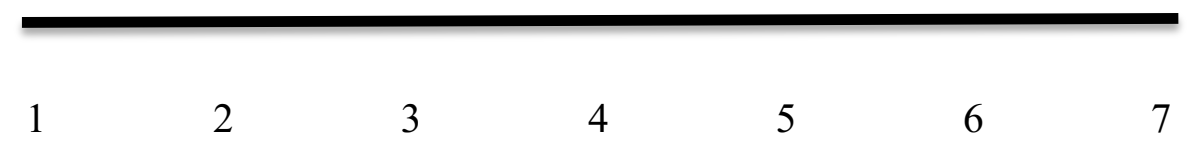


Appendix E

Movie Quiz - Set 1

There are 9 multiple-choice questions about the movie you just watched. Please choose the best answer for each question.

1. In the movie, a man is murdered. From where does the murderer jump out and kill him?
A. from behind a pillar
B. from behind a sofa
C. from under a table
D. from under a sofa

2. Where does the woman put her tool of defense after she and the child get to the bathroom?
A. on the ground
B. in the bathtub
C. in the sink
D. behind the heater

3. When the child sees the twin sisters in the hallway, what flashes before his eyes?
A. A vision of his parents
B. A vision of their death
C. A vision of his death
D. A vision of the blood on the elevator 
4. What does the man use to break into the door?
A. an axe
B. a chainsaw
C. a hammer
D. a picksaw

5. When riding in the hallway, the child sees a door and stops. What does he do next?
A. He tries to open the door but it is locked
B. He opens the door and sees the twin sisters
C. He stops for a while and then starts riding again
D. He puts his ear on the door and tries to listen to what happens inside.

6. What does the boy use to write on the door?
A. a lipstick
B. a chalk
C. a pen
D. a brush

7. Where does the child hide himself after he escapes from the bathroom?
A. in a compartment in the kitchen
B. in a cabinet in the common room
C. under the sofa in the common room
D. in the storage room in the kitchen

8. Why does the man not continue trying to kill the woman after he breaks the bathroom door?
A. because he hears people walking in the hallway
B. because he hears people talking in the hallway
C. because he hears people approaching from the outside
D. because he hears a vehicle approaching from the outside
9. In his mom's bedroom, the child picks up something from the bedside table. What does he pick up? 

A. a lipstick
B. a glass
C. a pen
D. a knife 
Memory Quiz - Set 2

There are 20 multiple-choice questions about the movie you watched on the first day of this experiment. Please choose the best answer for each question.

1. When the woman runs upstairs to look for the child, she sees two people in a bedroom; one of them is wearing a mask. What kind of mask is the person wearing?
A. ax ox mask
B. a pig mask
C. a deer mask
D. a goat mask

2. What is the name of the boy whom the child talks to after he meets the two girls in the hallway?
A. Johnny
B. Tony
C. Timmy
D. Bobby

3. While looking for the child, the woman sees a dead hotel occupant in the movie. What does he say to her?
A. "Come and join us"
B. "Love the dress"
C. "You are welcome here anytime"
D. "Great party, isn't it?"

4. What does the man say when he finds out that the woman is flipping through his typed pages on the desk?
A. How do you like the writing?
B. How do you like it?
C. What do you think about it? 
D. What do you think about the writing?

5. How many doors does the man destroy?
A. 1
B. 2
C. 3
D. 4

6. What does the woman use to defend herself in the bathroom when the man is trying to open the bathroom door?
A. a saw
B. a hammer
C. a knife
D. an axe

7. What does the man say after he breaks the bathroom door?
A. Here's Jacky!
B. Here's Johnny!
C. Here comes Jacky!
D. Here comes Johnny!

8. What is the woman horrified to read on all of the man's typed pages?
A. All job and no fun makes Jack a dull boy
B. All job and no drink makes Jack a dull boy
C. All work and no play makes Jack a dull boy
D. All work and no fun makes Jack a dull boy

9. Where does the child run when the man finds him out and starts chasing him?
A. a maze
B. a house
C. a castle
D. a park

10. How does the woman let the child out of the building while the man is trying break into the room? 

A. by letting the child slip through the window
B. by letting the child slip through the trash chute
C. by letting the child climb up the roof
D. by letting the child slide down the pipe

11. What does the child write to alarm the woman?
A. REDRUM
B. MURDER
C. redrum
D. murder

12. What is the child holding while he is writing on the door?
A. an axe
B. a knife
C. a pencil
D. a toy

13. What is the woman holding while she is flipping through the man's typed pages on the desk?
A. a knife
B. an axe
C. a saw
D. a bat

14. What do the two girls say to the child when they meet in the hallway?
A. Come and join us, Danny
B. Come and have fun with us, Danny
C. Come and play with us, Danny
D. Come and let's play forever, Danny

15. What is the number of the room the child encounters in the hallway while riding?
A. 287
B. 267
C. 237
D. 227

16. What does the man say after he breaks the bedroom door? 

A. Wendy, I'm home
B. Wendy, I'm coming
C. Wendy, I'm back
D. Wendy, I'm here

17. In the movie, the child sees the twin sisters are killed in the hallway. They are killed by
A. a knife
B. a bat
C. an axe
D. a saw

18. A man arrives at the building in a snow-clearing vehicle (snowplow). What does he say after he gets inside building?
A. Hello, anybody here?
B. Hello, what's going on here?
C. Hello, is there anybody here?
D. Hello, anyone living here?

19. What is the child seen riding on through the hallways?
A. Go-Kart
B. Roller Skates
C. Skateboard
D. Tricycle

20. What does the child say to his imaginary friend after he meets the twin sisters in the hallway?
A. I'm scared
B. It's very scary
C. This is very scary
D. I'm very scared 
Appendix F

Sleep Hour Rating Scale \& Question on Prior Exposure to the Movie before the

Experiment

Sleep Hour Rating Scale

Approximately how many hours of sleep did you get last night? Indicate your rating by clicking on 1 of the 7 boxes below. When you are done, press NEXT to proceed.

\begin{tabular}{ccccccc} 
Less than $4 \mathrm{hr}$ & $4 \mathrm{hr}$ & $5 \mathrm{hr}$ & $6 \mathrm{hr}$ & $7 \mathrm{hr}$ & $8 \mathrm{hr}$ & More than $8 \mathrm{hr}$ \\
\hline 1 & 2 & 3 & 4 & 5 & 6 & 7
\end{tabular}

Question on Prior Exposure

Have you ever seen this movie before the experiment? $0=$ no, $1=$ yes

No

Yes

0 


\section{Appendix G}

\section{Study Protocol}

Day 1

\section{Consent Form}

2. Demographic Information Form

3. Baseline Mood Rating

Please rate how you feel at this moment. Indicate your rating by clicking on 1 of the 7 boxes below. 1 =very calm, 7 = very anxious. When you are done, press NEXT to proceed.

4. Stressful Movie

\section{Memory Vividness Rating}

When recalling the movie, how vivid was your memory? Indicate your rating by clicking on 1 of the 7 boxes below: $1=$ not vivid at all, 7 = very vivid.

\section{Memory Anxiety Rating}

When recalling the movie, how anxious did the memory of the movie make you feel? Indicate your rating by clicking on 1 of the 7 boxes below: $1=$ not anxious at all, $7=$ very anxious.

7. Whether Seen the Movie Before

Have you ever seen this movie before the experiment? $0=$ no, $1=$ yes.

\section{Movie Valence Rating}

Please rate the valence of the movie, i.e., how positive or negative did the movie make you feel? 1 = highly negative, 4 = neutral, 7 = highly positive

9. Movie Arousal Rating 
Please rate the arousal of the movie, i.e., how aroused did the movie make you feel? 1 = highly calming, 4 = neutral (neither calming nor arousing), 7 = highly arousing.

\section{Memory Quiz Set 1}

There are 9 multiple-choice questions about the movie you just watched. Please choose the best answer for each question.

Day 2 - Reminder/Positive and Reminder/Neutral Groups

\section{Movie Reminder}

Today you will first watch an excerpt from yesterday's movie. Then you will watch a new movie and complete a set of questionnaires. Please click NEXT when you are ready to begin.

2. (Three minutes later) Positive or Neutral Movie

\section{Movie Valence Rating}

Please rate the valence of the movie, i.e., how positive or negative did the movie make you feel? 1 = highly negative, $4=$ neutral, 7 = highly positive.

4. Movie Arousal Rating

Please rate the arousal of the movie, i.e., how aroused did the movie make you feel? 1 = highly calming, 4 = neutral (neither calming nor arousing), 7 = highly arousing.

\section{Sleep Hour Question}

Approximately how many hours of sleep did you get last night? Indicate your rating by clicking on 1 of the 7 boxes below.

No Reminder/Positive and No Reminder/Neutral Groups

1. Positive or Neutral Movie 
Today you will first watch a movie and then complete a set of questionnaires. Please click NEXT when you are ready to begin.

2. Movie Valence Rating

Please rate the valence of the movie, i.e., how positive or negative did the movie make you feel? 1 = highly negative, $4=$ neutral, 7 = highly positive.

3. Movie Arousal Rating

Please rate the arousal of the movie, i.e., how aroused did the movie make you feel? 1 = highly calming, 4 = neutral (neither calming nor arousing), 7 = highly arousing.

\section{Sleep Hour Question}

Approximately how many hours of sleep did you get last night? Indicate your rating by clicking on 1 of the 7 boxes below.

\section{Day 3}

\section{Memory Vividness Rating}

Recall the stressful movie you watched on the first day of this experiment. Bring it to mind as if you were watching it right now. In a moment, the screen will go blank for 30 seconds. While the screen is blank, please recall the movie as best as you can.

When recalling the stressful movie, how vivid was your memory? Indicate your rating by clicking on 1 of the 7 boxes below. $1=$ not vivid at all, $7=$ very vivid.

\section{Memory Anxiety Rating}

When recalling the stressful movie, how anxious did the memory of the movie make you feel? Indicate your rating by clicking on 1 of the 7 boxes below. $1=$ not anxious at all, 7 = very anxious.

\section{Sleep Hour Question}

Approximately how many hours of sleep did you get last night? Indicate your 
rating by clicking on 1 of the 7 boxes below.

4. Memory Quiz Set 2

There are 20 multiple-choice questions about the movie you watched on the first day of this experiment. Please choose the best answer for each question. 


\section{References}

Agren, T. (2014). Human reconsolidation: A reactivation and update. Brain Research Bulletin, 105, 70-82. http://doi.org/10.1016/j.brainresbull.2013.12.010

Agren, T., Engman, J., Frick, A., Björkstrand, J., Larsson, E.-M., Furmark, T., \& Fredrikson, M. (2012). Disruption of reconsolidation erases a fear memory trace in the human amygdala. Science, 337, 1550-1552. http://doi.org/10.1126/science.1223006

Besnard, A., Caboche, J., \& Laroche, S. (2012). Reconsolidation of memory: A decade of debate. Progress in Neurobiology, 99, 61-80. http://doi.org/10.1016/j.pneurobio.2012.07.002

Burnham, W. H. (1903). Retroactive amnesia: Illustrative cases and a tentative explanation. American Journal of Psychology, 14, 118-132.

Coccoz, V., Maldonado, H., \& Delorenzi, A. (2011). The enhancement of reconsolidation with a naturalistic mild stressor improves the expression of a declarative memory in humans. Neuroscience, 185, 61-72. http://doi.org/10.1016/j.neuroscience.2011.04.023

Datto, C. J. (2000). Side effects of electroconvulsive therapy. Depression and Anxiety, 12, 130-134. http://doi.org/10.1002/1520-6394(2000)12:3<130::AID$\mathrm{DA} 4>3.0 . \mathrm{CO} ; 2-\mathrm{C}$

Di Bona, V. J. (Director). (1989). America's Funniest Home Videos. [Television series]. California: ABC Entertainment. 
Dolcos, F., Labar, K. S., \& Cabeza, R. (2005). Remembering one year later: Role of the amygdala and the medial temporal lobe memory system in retrieving emotional memories. Proceedings of The National Academy of Sciences, 102, 2626-2631. http://doi.org/10.1073/pnas.0409848102

Dudai, Y. (2004). The neurobiology of consolidations, or, how stable is the engram? Annual Review of Psychology, 55, 51-86. http://doi.org/10.1146/annurev.psych.55.090902.142050

Eldridge, L. L., Sarfatti, S., \& Knowlton, B. J. (2002). The effect of testing procedure on remember-know judgments. Psychonomic Bulletin \& Review, 9, 139-145.

Furman, O., Dorfman, N., Hasson, U., Davachi, L., \& Dudai, Y. (2007). They saw a movie: Long-term memory for an extended audiovisual narrative. Learning \& Memory, 14, 457-467. http://doi.org/10.1101/lm.550407

Gray, P. (2011). Psychology (6th Ed.). New York, NY: Worth Publishers.

Gross, J. J., \& Levenson, R. W. (1995). Emotion elicitation using films. Cognition \& Emotion, 9, 87-108. http://doi.org/10.1080/02699939508408966

Hupbach, A., Gomez, R., Hardt, O., \& Nadel, L. (2007). Reconsolidation of episodic memories: A subtle reminder triggers integration of new information. Learning \& Memory, 14, 47-53.

Hupbach, A., Hardt, O., Gomez, R., \& Nadel, L. (2008). The dynamics of memory: Context-dependent updating. Learning \& Memory, 15, 574-579. http://doi.org/10.1101/1m.1022308 
Jones, C. E., \& Monfils, M.-H. (2013). Using reconsolidation and extinction to weaken fear memories in animal models. In C. M. Alberini (Ed.), Memory reconsolidation (pp. 165-181). Waltham, MA: Academic Press.

Kensinger, E. A., \& Schacter, D. L. (2008). Memory and emotion. In M. Lewis, J. M. Haviland-Jones, \& L. F. Barrett (Eds.), Handbook of Emotions (3rd ed., pp. 601617). New York, NY: Guilford Press.

Kindt, M., \& Soeter, M. (2013). Reconsolidation in a human fear conditioning study: A test of extinction as updating mechanism. Biological Psychology, 92, 43-50. http://doi.org/10.1016/j.biopsycho.2011.09.016

Kindt, M., Soeter, M., \& Vervliet, B. (2009). Beyond extinction: Erasing human fear responses and preventing the return of fear. Nature Neuroscience, 12, 256-258. http://doi.org/10.1038/nn.2271

Koller, W. C., \& Vetere-Overfield, B. (1989). Acute and chronic effects of propranolol and primidone in essential tremor. Neurology, 39, 1587-1587. http://doi.org/10.1212/WNL.39.12.1587

Kroes, M. C. W., Tendolkar, I., van Wingen, G. A., van Waarde, J. A., Strange, B. A., \& Fernández, G. (2014). An electroconvulsive therapy procedure impairs reconsolidation of episodic memories in humans. Nature Neuroscience, 17, 204-206. http://doi.org/10.1038/nn.3609

Kubrick, S. (Producer), \& Kubrick, S. (Director). (1980). The Shining. [Motion picture]. United States: The Producer Circle Co.

LaBar, K. S., \& Cabeza, R. (2006). Cognitive neuroscience of emotional memory. Nature Reviews Neuroscience, 7, 54-64. http://doi.org/10.1038/nrn1825 
Lee, J. L. C. (2009). Reconsolidation: Maintaining memory relevance. Trends in Neurosciences, 32, 413-420. http://doi.org/10.1016/j.tins.2009.05.002

Lewis, D. J., Bregman, N. J., \& Mahan, J. J. (1972). Cue-dependent amnesia in rats. Journal of Comparative and Physiological Psychology, 81, 243-247.

Luttges, M. W., \& McGaugh, J. L. (1967). Permanence of retrograde amnesia produced by electroconvulsive shock. Science, $156,408-410$.

Magidson, M. (Producer), \& Fricke, R. (Director). (1993). Baraka. [Documentary]. United States: The Samuel Goldwyn Company.

Mathot, S., Schreij, D., \& Theeuwes, J. (2012). OpenSesame: An open-source graphical experiment builder for the social sciences. Behavior Research Methods, 44, 314-324. http://doi.org/10.3758/s13428-011-0168-7

McGaugh, J. L. (1966). Time-dependent processes in memory storage. Science, 153, $1351-1358$.

McGaugh, J. L. (2000). Memory-a Century of Consolidation. Science, 287, 248-251. McGaugh, J. L. (2006). Make mild moments memorable: Add a little arousal. Trends in Cognitive Science, 10, 345-347.

McNally, R. J. (2003). Remembering trauma. Cambridge, MA: The Belknap Press of Harvard University Press.

Misanin, J. R., Miller, R. R., \& Lewis, D. J. (1968). Retrograde amnesia produced by electroconvulsive shock after reactivation of a consolidated memory trace. Science, $160,554-555$. 
Monfils, M.-H., Cowansage, K. K., Klann, E., \& LeDoux, J. E. (2009). Extinctionreconsolidation boundaries: Key to persistent attenuation of fear memories. Science, 324, 951-955. http://doi.org/10.1126/science.1167975

Nader, K., \& Einarsson, E. O. (2010). Memory reconsolidation: An update. Annals of the New York Academy of Sciences, 1191, 27-41. http://doi.org/10.1111/j.1749$6632.2010 .05443 . x$

Nader, K., Schafe, G. E., \& LeDoux, J. E. (2000). Fear memories require protein synthesis in the amygdala for reconsolidation after retrieval. Nature, 406, 722-726.

Nies, A. S., \& Shand, D. G. (1975). Clinical pharmacology of propranolol. Circulation, 52, 6-15. http://doi.org/10.1161/01.CIR.52.1.6

Phelps, E. A. (2004). Human emotion and memory: Interactions of the amygdala and hippocampal complex. Current Opinion in Neurobiology, 14, 198-202. http://doi.org/10.1016/j.conb.2004.03.015

Ribot, T. (1882). Diseases of memory: An essay in the positive psychology. (W. H. Smith, Trans.). New York, NY: Appleton.

Sara, S. J. (2000). Retrieval and Reconsolidation: Toward a neurobiology of remembering. Learning \& Memory, 7, 73-84. http://doi.org/10.1101/1m.7.2.73

Sharot, T., Delgado, M. R., \& Phelps, E. A. (2004). How emotion enhances the feeling of remembering. Nature Neuroscience, 7, 1376-1380. http://doi.org/10.1038/nn1353

Schiller, D., Kanen, J. W., LeDoux, J. E., Monfils, M.-H., \& Phelps, E. A. (2013). Extinction during reconsolidation of threat memory diminishes prefrontal cortex involvement. Proceedings of the National Academy of Sciences, 110, 20040-20045. http://doi.org/10.1073/pnas.1320322110 
Schiller, D., Monfils, M.-H., Raio, C. M., Johnson, D. C., LeDoux, J. E., \& Phelps, E. A. (2010). Preventing the return of fear in humans using reconsolidation update mechanisms. Nature, 463, 49-54.

Schwabe, L., Nader, K., \& Pruessner, J. (2013). ß-Adrenergic blockade during reactivation reduces the subjective feeling of remembering associated with emotional episodic memories. Biological Psychology, 92, 227-232.

Schwabe, L., Nader, K., Wolf, O. T., Beaudry, T., \& Pruessner, J. C. (2012). Neural signature of reconsolidation impairments by propranolol in humans. Biological Psychiatry, 71, 380-386. http://doi.org/10.1016/j.biopsych.2011.10.028

Squire, L. R., Slater, P. C., \& Chace, P. M. (1976). Reactivation of recent or remote memory before electroconvulsive therapy does not produce retrograde amnesia. Behavioral Biology, 18, 335-343.

Walker, M. P., Brakefield, T., Hobson, J. A., \& Stickgold, R. (2003). Dissociable stages of human memory consolidation and reconsolidation. Nature, 425, 616-620.

Wichert, S., Wolf, O. T., \& Schwabe, L. (2013). Updating of episodic memories depends on the strength of new learning after memory reactivation. Behavioral Neuroscience, 127, 331-338. http://doi.org/10.1037/a0032028 